This is the post print version of the article, which has been published in Aging Clinical and Experimental Research. 2019, 31(1), 75-83.

http://dx.doi.org/10.1007/s40520-018-0946-5

Th This document has been downloaded from TamPub.tatifi The Institutional Repository of University of Tampere

\title{
ELEVATED POST-VOID RESIDUAL VOLUME IN A GERIATRIC POST-HIP FRACTURE ASSESSMENT IN WOMEN -ASSOCIATED FACTORS AND RISK OF MORTALITY
}

Maria Nuotio'MD, PhD

Chief, Department of Geriatric Medicine

Seinäjoki Central Hospital

Seinäjoki, Finland

Tiina Luukkaala, MSc

Biostatistician

Science Center, Pirkanmaa Hospital District, Tampere

School of Health Sciences,

University of Tampere, Finland

Teuvo Tammela, MD, PhD

Professor and Chairman

Department of Surgery

Faculty of Medicine and Life Sciences

University of Tampere and

Tampere University Hospital,

Tampere, Finland

Corresponding author:

Maria Nuotio

Department of Geriatric Medicine

Seinäjoki Central Hospital

Hanneksenrinne 7

60220 SEINÄJOKI

Finland

Phone: +358503536024

E-mail: maria.nuotio@ fimnet.fi

Key words: detrusor underactivity, post-void residual, hip fracture, physical functioning, geriatric assessment

Running title: Residual volume and post-hip fracture assessment 


\section{ABSTRACT}

Background and Aim: Multiple factors contribute to elevated post-void residual urine volumes (PVR) but they may indicate detrusor underactivity (DU), especially in older women. The aim here was to examine factors associated with and prognostic significance of elevated PVR in a geriatric post-hip fracture assessment in a female population.

Methods: Consecutive female hip fracture patients $(n=409)$ aged 65 years and older were included. PVR was measured by bladder scanner. PVR of $160 \mathrm{ml}$ or more was deemed elevated. Ageadjusted univariate logistic regression analyses were conducted to examine the association of the domains of the comprehensive geriatric assessment (CGA) with elevated PVR. Cox proportional hazards model was used to determine the age-adjusted association of an elevated PVR with oneyear mortality.

Results: Of the patients 64 (15.6\%) had elevated PVR. Having urinary or faecal incontinence, difficulties in physical activities of daily living, malnutrition, poor performance on Timed Up and Go and Elderly Mobility Scale were significantly associated with elevated PVR. Difficulties in instrumental activities of daily living, renal dysfunction, constipation, polypharmacy, nocturia, cognitive impairment and depressive mood were not associated with elevated PVR. Elevated PVR significantly increased the risk of mortality one year post-hip fracture.

Conclusions: Elevated PVR is relatively common in older female hip fracture patients and associated with physical functioning, malnutrition and risk of mortality. Even though a causal relationship cannot be confirmed, the findings may suggest a relationship between DU and physical frailty. PVR deserves to be included in the CGA of frail older patients including women. 


\section{INTRODUCTION}

Urinary dysfunction related to both storage and voiding phases of the micturition cycle is common among older people. Among storage symptoms, urinary incontinence (UI), particularly urgency incontinence (UUI), is acknowledged as one of the major geriatric syndromes with considerable impacts on functional ability, quality of life, prognosis and costs to the social and health care services of aging societies [1]. Nocturia is also considered a multifactorial symptom entity in its own right [2]. Voiding symptoms are known to be frequent, especially in older men due to bladder outlet obstruction (BOO) related to benign prostatic enlargement (BPE) caused by benign prostatic hyperplasia (BPH). However, voiding symptoms are not BPE or gender specific since older men without BOO and older women may also report similar symptoms $[3,4]$.

Detrusor underactivity (DU) is a poorly understood geriatric condition which has received relatively little attention either clinically or in research $[5,6]$. According to a definition proposed by the International Continence Society (ICS), DU is characterized as a contraction of reduced strength and/or duration of the detrusor resulting in prolonged bladder emptying and/or failure to achieve complete bladder emptying within a normal time span [7]. The prevalence of DU is believed to be high in frail and institutionalized older individuals and may be accompanied by detrusor overactivity (DO), leading to a complex condition known as detrusor hyperactivity with impaired contractility (DHIC) [8].

Elevated post-void residuals (PVRs) in older patients are multifactorial in nature [5,6]. Moreover, the causative and predisposing factors may differ between men and women. Constipation or medications causing problems in bladder emptying may underlie the finding in both sexes $[9,10]$. Elevated PVR may also indicate DU. PVR can be easily measured on portable ultrasound devices [11]. The method is noninvasive, patient friendly, and yields reliable results. In men, elevated PVRs may suggest BOO attributed to BPE and the measure cannot be differentiated from elevated PVRs related to DU. In women, BOO is more uncommon and elevated PVRs may be consequently more likely to be associated with DU. Lack of estrogen has also been suggested as one possible mechanism of DU in older women (6).

Hip fractures in older individuals typically affect multimorbid and frail patient population. The aim of the present study were to examine the prevalence and factors associated with elevated PVRs in a consecutive series of female patients invited to a comprehensive geriatric assessment (CGA) in an 
outpatient setting 4-6 months after sustaining a hip fracture. In addition, we aimed to assess the prognostic significance of an elevated PVR for hip fracture mortality.

\section{MATERIAL AND METHODS}

As a part of an established local care pathway, all hip fracture patients aged 65 years and over suffering their first hip fracture between January 2011 and April 2015, were invited for a CGA at the geriatric outpatient clinic 4-6 months (median 6 months; Interquartile Range [IQR] 4-6 months) after the hip fracture. All the hip fracture patients in the area, with a population of some 200000 , are treated in our hospital. The process of the outpatient assessment has been described in greater detail elsewhere [12]. A physiotherapist's assessment precedes the geriatric assessment. Patients' preoperative American Society of Anesthesiologists (ASA) scores [13] were used to assess the general health status. There are five classes: 1) healthy person, 2) mild systemic disease, 3) severe systemic disease, 4) severe systemic disease that is a constant threat of life, and 5) a moribund person who is not expected to survive without the operation.

At the outpatient clinic, standardized and well-known measures were used for different domains for the CGA [12]. Briefly, cognitive function was measured by the Mini Mental State Examination (MMSE) [14], depressive mood on the 15-item Geriatric Depression Scale (GDS-15) [15], activities of daily living on the Physical Activities of Daily Living Index (PADL) introduced by Katz [16] and Instrumental Activities of Daily Living (IADL) by Lawton and Brody [17], nutritional status on the short and long forms of the Mini Nutritional Assessment (MNA-SF and MNA-LF) [18]. Number of regularly taken medications at the time of the fracture was registered and any urinary and faecal incontinence or constipation were elicited. Based on questions on different types of urinary incontinence, stress urinary incontinence (SUI) was defined as having urinary leakage during physical exertion such as coughing or lifting, and UUI as having urinary leakage associated with an urgency to urinate. Mixed urinary incontinence was defined as a combination of the SUI and UUI. Nocturia was defined as the number of voids during the night. Renal function was assessed by calculating the estimated Glomerular Filtration Rate as according to the Cockroft and Gault formula (eGFR) [19].

In the physiotherapist's assessment, Timed Up and Go (TUG) [20] was measured both as time and as categorized by the examining physiotherapist. In addition, mobility was assessed and categorized on the Elderly Mobility Scale (EMS) [21]. Muscle strength was measured as grip strength in the stronger hand with Jamar dynamometer. Grip strength less than $16 \mathrm{~kg}$ in the stronger hand was 
defined as weakened [22]. The categorization of the variables used in the CGA and physiotherapist's assessment appears in Table 2.

There is no exact definition of elevated PVR. In younger adult patients a PVR of 50-100 ml or more is deemed elevated [6]. In older patient populations a clearly higher PVR is accepted. Definitions of elevated PVR in the literature vary from $150 \mathrm{ml}$ to $200 \mathrm{ml}$ or more [6]. The PVR limit value used in clinical decision-making may be even higher, especially in the frail female patient population. It has been proposed that generally a PVR of more than half of the bladder capacity should lead to interventions [6]. The dependent variable of elevated PVR in the present study was defined as PVR $160 \mathrm{ml}$ or more as measured transabdominally immediately after micturation using a portable bladder scanner. A limit value of $160 \mathrm{ml}$ was chosen based on calculations on specificity and sensitivity with an $80 \%$ percentile.

The baseline and one-year mobility level were defined in a similar way. It was categorized as 1) ability walk outdoors unassisted, 2) ability walk indoors unassisted, 3) ability to walk assisted only or 4) unable to walk. The change in the mobility level between the time of the fracture and one year thereafter was defined as declined vs. same or improved mobility level. The data on mobility level were collected by a geriatric nurse trained for the purpose.

Dates of death for the mortality analysis were extracted from the electronic patient files. There were no losses to mortality follow-up. The study was approved by the Ethics Committee of Hospital District of Southern Ostrobothnia. All the patients or their representatives gave informed consent.

A dropout analysis was carried out comparing the baseline characteristics among the attendees, nonattendees, and the patients who had died before follow-up (Table 1). Differences between groups were calculated by Fisher's exact test in the cases of categorical variables. Linear associations of continuous variables were evaluated by Spearman's correlation coefficients (rho). A p-value of $<0.05$ was considered statistically significant.

In order to examine the association of each domain of the CGA with an elevated PVR, age-adjusted univariate logistic regression models were used introducing each variable separately into the model with odds ratios (OR) and 95\% confidence intervals (CI). Age-adjusted association of an elevated PVR with one-year mortality was assessed with Cox regression hazards models showing results by hazard ratios (HR) with 95\% confidence intervals (CI). In addition, an age- and baseline mobility level -adjusted multinomial logistic regression analysis with ORs and CIs was constructed to examine the association of elevated PVR with decline in mobility vs. same on improved mobility level and 
mortality one year post-hip fracture. All statistical analyses were performed using IBM SPSS Statistics version 23 (IBM SPSS Statistics, IBM Corporation, Chicago, IL).

\section{RESULTS}

Of the 663 patients 17\% had died before the follow-up. Of the survivors, 75\% (409) attended the outpatient assessment. Compared to the attendees, the non-attendees and the deceased patients were more likely to have higher ASA scores, greater number of regularly taken medications, poorer nutritional status according to the MNA, and they were more likely to need assistance in walking and to be living in assisted living accommodation or in an institution at baseline. (Table 1)

Of the 409 patients $64(15.6 \%)$ had an elevated PVR as measured by the bladder scanner. The median PVR was $29 \mathrm{ml}$ (IQR 5-93ml, range 0-855 ml).

The distribution of the domains of the CGA and the tests included in the physiotherapist's assessment according the dichotomized PVR variable are shown in Table 2. The results of the ageadjusted univariate logistic regression analyses for the associations of each the independent variable with an elevated PVR are also shown in Table 2. Of the CGA domains, having any or UUI, faecal incontinence, difficulties in PADLs and malnutrition measured either by the short or long form of the MNA were significantly associated with elevated PVR. Of the tests conducted by the physiotherapist, both longer time or markedly abnormal score on the TUG and the poorest result on the EMS were significantly associated with elevated PVR. Renal dysfunction, number of medications, nocturia, constipation, cognitive impairment, depressive mood, difficulties in IADLs and weakened grip strength were not significantly associated with elevated PVR. Of the patients 13 (20.3\% of those with elevated PVR) had a PVR greater than $400 \mathrm{ml}$ and of these 10 (76.9\%) reported urinary incontinence.

Increased PVR was linearly associated with weakened grip strength among women aged 80-89 years (Spearman's rho=-0.149, $\mathrm{p}=0.039, \mathrm{n}=193$ ), but not among women aged 65-79 and over 90 years (rho $=-0.051, \mathrm{p}=0.627, \mathrm{n}=94$ and $\mathrm{rho}=0.054,9=0.711, \mathrm{n}=50$ respectively).

Of the patients with elevated PVR, compared to the patients with non-elevated PVR, $12.5 \%(\mathrm{n}=9)$ vs. $2.6 \%(\mathrm{n}=8)(\mathrm{p}=0.002)$ had died within one year of the hip fracture. In the age-adjusted Cox proportional hazards model, patients with elevated PVR had an increased risk of death within one year of the hip fracture (HR 4.35; 95\% CI 1.57-12.03) (Figure 1). 
In the additional multinomial age-and baseline mobility level -adjusted regression model, elevated PVR was associated with both declined mobility ( $\mathrm{n}=131)$ (OR 1.95;95\%CI 1.05-3.61) and mortality (OR 4.50;95\%CI 1.50-13.5) one year post-hip fracture.

\section{DISCUSSION}

The essential finding of this study was the association of elevated PVR in a substantial number of consecutive older female hip fracture patients with functional and mobility disability, both urinary and faecal incontinence, and malnutrition. The association of elevated PVR with mortality one year post-hip fracture corroborates an earlier observation of the predictive value of postoperative urinary retention in older female hip fracture patients [23].

Elevated PVR was not uncommon in our patient population. Very few studies have addressed the prevalence of elevated PVRs or urinary retention in older female populations. Most studies on urinary retention in hip fracture patients have concentrated on the immediate peri- and postoperative phase of hip fracture care where prevalences have been higher and volumes of urinary retention have been greater than those reported in the present study $[23,24]$. One study reported a prevalence of $20 \%$ in the recovery phase of older female hip fracture patients, a figure relatively close to that reported in our study [23]. Given that the non-attendees were more incapacitated [12]), the result of our study on the prevalence of elevated PVRs may include a selection bias. Due to the association of elevated PVR with disability, the bias is more likely to involve underreporting than overreporting.

We found a strong association between elevated PVR and the tests conducted by the physiotherapist on patients' mobility. Overall poorer scores on TUG and EMS predicted elevated PVR. An association between elevated PVR and impaired mobility has been reported in older female hospitalized patients [25]. Moreover, older female hip fracture patients without perioperative urinary retention (POUR) showed significantly better motor and total Functional Independence Measure (FIM) gains on discharge compared with females with POUR [24]. Even though no association between weakened grip strength and elevated PVR was observed in the cohort as a whole, our tests revealed a weak, but statistically significant linear association between elevated PVR and weakened grip strength in the age group of 80-89 years. Interestingly, an association was observed between elevated PVR and declined mobility one year post-hip fracture. It is worth noting that, in the present study, an association emerged between elevated PVR and indicators of physical functioning but not between those of psychocognitive domains. 
There was an association between elevated PVR and reporting any urinary incontinence.

Difficulties in bladder emptying may lead in the most severe cases to overdistention of the detrusor resulting in overflow urinary incontinence [10]. In the present study, the PVR exceeded the usual bladder capacity of $400 \mathrm{ml}$ in one fifth of the patients with elevated PVR and a significant proportion of these patients reported urinary incontinence eventually suggesting an overflow situation.

An association was observed of elevated PVR with UUI but not with SUI. A similar finding has been reported in a study on risk factors for elevated PVR in women with urgency symptoms [26]. The finding may be explained by the close relationship between DO and DU [27] and may imply DHIC, a condition originally described by Resnick and Yalla as early as in 1987 [8]. Up to two thirds of frail older patients living in nursing homes have been estimated to suffer from DHIC. In a more recent study, history of back surgery or injury and pelvic surgery were found to be associated with difficulties in bladder emptying in older women with symptoms of an overactive bladder (OAB) [28]. Elevated PVR was not significantly associated with nocturia, implying that its etiology was beyond the urinary bladder [29].

We demonstrated an association between elevated PVR and faecal incontinence, which again emphasizes the association between DU and disability. Constipation may be a contributory factor for both difficulties in bladder emptying and incontinence, either urinary and/or faecal [9]. In an earlier study, an association was found between elevated PVR and constipation in older female inpatients [25]. We found no such association.

The strengths of our study include significant series of patients enabling a sample size big enough to ensure sufficient statistical power and use of well-known and standardized measures in the CGA. The measurement of PVR was conducted in a similar way in all participants. Moreover, the mortality data were complete. There are also a number of limitations to the study. First of all, the sample represents a selected sample of hip fracture patients, which may have affected the reliability of the findings. According to our dropout analysis, a significant proportion of the most severely disabled patients had either died before follow-up or were among the non-attendees. Second, comorbidities were not recorded in detail and except for ASA scores, no indices for comorbidities were used. For example, diabetes and degenerative back diseases are known to impair the contractility of the urinary bladder and urinary dysfunction may also occur in neurological disorders common in older people [10]. In addition, even though BOO is known to be more frequent in older men than in women, BOO in women may sometimes occur in cases of pelvic prolapses. These were not examined in our patient population. Third, we only examined the association of total number of 
regularly taken medications with elevated PVR. Several medications may impair the contractility of the urinary bladder, especially those with anticholinergic properties [10]. Fourth, the PVRs were not assessed at the time of the fracture and thus changes in the PVRs between the time of the acute hip fracture care and follow-up could not be examined. Also, we focused on examining the female population. This was mainly done because we were unable to exclude the possible effect of BOO related to BPE in male patients. Nevertheless, we did conduct analyses for the male population $(n=145)$ but only higher age and moderate renal dysfunction as measured by the estimated GFR were significantly associated with elevated PVR. Quite expectedly, the prevalence of an elevated PVR of $27.6 \%$ in men was higher than that in women. Interestingly, unlike in women, elevated PVR did not predict mortality in men. This concurs with a study by Adunsky and colleagues [24]. The differences in the findings between the genders imply different etiological pathways associated with elevated PVR. Finally, due to small number of cases, the confidence intervals in the mortality analyses were relatively wide and therefore the results should be interpreted with some caution.

Given the association between urinary incontinence, the UUI in particular, and elevated PVR, the possibility of DU should be taken into account when planning treatments for UI in frail older patients. Patients with DU may be at risk of further urinary retention when taking UI medications, especially antimuscarinics. These medications are known to carry a risk of a number of other harmful effects in the frail patient population [10]. Mirabegron, a beta3 adrenoreceptor agonist, is a novel UUI medication lacking the harmful effects associated with antimuscarinics and may less likely increase the PVRs [30]. As urinary retention may exacerbate renal dysfunction and increase the risk of urinary tract infections, urinary drainage, ideally by means of intermittent urinary catheterization should be carried out in cases of extremely large PVRs approaching or exceeding the normal bladder capacity. Moreover, the likelihood of overflow urinary incontinence has to be kept in mind. When BOO is suspected, either in women or in men, a gynecologist or a urologist need to be consulted.

\section{CONCLUSIONS}

Elevated PVR is relatively common and associated with physical functioning, malnutrition and risk of mortality in older female hip fracture patients. Even though a causal relationship cannot be confirmed, the observations may suggest a connection between DU and physical frailty and highlight the prognostic significance and the syndromic nature of DU. Clinically it would be appropriate to include a PVR measurement in the CGA at least in the frail older patients with disabilities, including women. Further studies are needed to investigate the effect of different groups of medications on elevated PVR and to examine the role of frailty and sarcopenia in the development of DU in the older population. 


\section{ACKNOWLEDGEMENTS}

Ms Kaisu Haanpää, RN, is gratefully acknowledged for her expert collecting and saving of the data.

\section{ETHICAL STATEMENT}

This work was supported by Research Fund of the Hospital District of Southern Ostrobothnia and the State Research Financing of Seinäjoki Central Hospital. The authors declare that they have no conflicts of interest. The study design was approved by the Ethics Committee of the Hospital District of Southern Ostrobothnia. Informed consent was obtained from all the participants or their representatives. The study complies with the ethical standards of the Declaration of Helsinki and its later amendments.

\section{REFERENCES}

[1] Milsom I, Cayne KS, Nicholson, S, Kvasz M, Chen CI, Wein AJ. Global prevalence and economic burden of urgency urinary incontinence: a systematic review. Eur Urol 2014;65:79-95.

[2] van Kerrebroeck P, Abrams P, Chaikin D, Donovan J, Fonda D, Jackson S, et al. The standardisation of terminology in nocturia: report from the Standardisation Sub-committee of the International Continence Society. Neurourol Urodyn 2002;21:179-183.

[3] Nuotio M, Jylhä M, Luukkaala T, Tammela TL. Urgency, urge incontinence and voiding symptoms in men and women aged 70 years and over. BJU Int 2002 Mar;89(4):350-5.

[4] Ding YY, Lieu PK, Choo PW. Is the bladder 'an unreliable witness' in elderly males with persistent lower urinary tract symptoms? Geriatr Nephrol Urol 1997;7:17-21.

[5] Osman NI, Chapple CR, Abrams P, Dmochowski R, Haab F, Nitti V, et al. Detrusor underactivity and the underactive bladder: a new clinical entity? A review of current terminology, definitions, epidemiology, aetiology and diagnosis. Eur Urol 2014;65:389-398.

[6] Taylor JA, Kuchel A. Detrusor underactivity clinical features and pathogenesis of an underdiagnosed geriatric condition. J Am Geriatr Soc 2006;54:1920-1932.

[7] Abrams P, Cardozo L, Fall M, Griffiths D, Rosier P, Ulmsten U, et al. The standardization of terminology of lower urinary tract function: report from the Standardization Sub-committee of the International Continence Society. Neurourol Urodyn 2002;21:167-178. 
[8] Resnick NM, Yalla SV. Detrusor hyperactivity with impaired contractile function. An unrecognized but common cause of incontinence in elderly patients. JAMA 1987;257:3076-3081.

[9] Vazque Roque M,Bouras EP. Epidemiology and management of chronic constipation in elderly patients. Clin Interv Aging 2015;10:919-30.

[10] DuBeau CE, Kuchel GA, Johnston T 2nd, Palmer MH, Wagg A, et al. Incontinence in the frail elderly:report from the $4^{\text {th }}$ International Consultation on Incontinence. Neurourol Urodynam 2010;29;165-178.

[11] Coombes GM, Millard RJ. The accuracy of portable ultrasound scanning in the measurement of residual urine volume. J Urol 1994;152:2083-2085.

[12] Nuotio M, Luukkaala T. Factors associated with changes in mobility and living arrangements in a comprehensive geriatric outpatient assessment after hip fracture. Disabil Rehab 2016; 38:11251133.

[13] Sankar A, Johnson S, Beattie W, Tait G, Wijeysundera D. Reliability of the American Society of Anesthesiologists physical status scale in clinical practice. Br J Anaest 2014 Apr; 113(3): 424432.

[14] Folstein MF, Folstein SE, McHugh PR. "Mini-mental State". A practical method for grading the cognitive state of patients for the clinician. J Psychiatr Res 1975;12:189-198.

[15] Brown L, Schinka J. Development and initial validation of a 15-item informant version of the Geriatric Depression Scale. In J Geriatr Psychiatry 2005;29:911-918.

[16] Katz S, Akpom CA. Index of ADL. Med Care 1976;13:782-788.

[17] Lawton MP, Brody EM. Assessment of older people: self-maintaining and instrumental activities of daily living. The Gerontologist 1969; 9:179-186.

[18] Guigoz Y. The Mini Nutritional Assessment (MNA) review of the literature-what does it tell us. J Nutr Health Aging 2006;10:466-485.

[19] Cockroft DW, Gault MG. Prediction of creatinine clearance from serum creatinine. Nephron 1976;16:31-41.

[20] Mathias S, Nayak U, Isaacs B. Balance in elderly patients: "the get-up and go" test. Arch Phys Med Rehabil 1986 Jun; 67(6): 387-389 
[21] Smith R. Validation and Reliability of the Elderly Mobility Scale. Physiotherapy 1994 Nov; 90(11): 744-747.

[22] Alley DE, Shardell MD, Peters KW, McLean RR, Dam TT, Kenny AM, et al. Grip strength cutpoints for the identification of clinically relevant weakness. J Gerontol A Biol Sci Med Sci 2014;69:559-566.

[23] Smith NK, Albazzaz MK. A prospective study of urinary retention and risk of death after proximal femoral fracture. Age Ageing 1996;25:150-154.

[24] Adunsky A, Nenaydenko O, Koren-Morag N, Puritz L, Fleissig Y, Arad M. Perioperative urinary retention, short-term functional outcome and mortality rates of elderly hip fracture patients. Geriatr Gerontol Int 2015;15:65-71.

[25] Tan TL, Lieu Pk. Ding YY. Urinary retention in hospitalized older women. Ann Acad Med Singapore 2001;30:588-592.

[26] FitzGerald MP, Jaffar J, Brubaker L. Risk factors for an elevated postvoid residual urine volume in women with symptoms of urinary urgency, frequency and urge incontinence. Int Urogynecol J 2001:237-240.

[27] Griffiths DJ, McCracken PN, Harrison GM, Gormley EA, Moore KN. Urge incontinence and impaired detrusor contractility in the elderly. Neurourol Urodynam 2002;21:126-131.

[28] Park J, Palmer MH. Factors associated with incomplete bladder emptying in older women with overactive bladder symptoms. J Am Geriatr Soc 2015: 63;1426-1431.

[29] Bosch JL, Weiss JP. The prevalence and causes of nocturia. J Urol 2013;189:S86-92.

[30] Yamaguchi O. Latest treatment for lower urinary tract dysfunction:Therapeutic agents and mechanism of action. Int J Urol 2013;20:28-39.

\section{FIGURE CAPTION}

Fig1. Age-adjusted 1-year mortality according to the post-void residual volume by cut-off value $160 \mathrm{ml}$ among women $(\mathrm{N}=409)$. 
Table 1. Dropout analysis of the study population $(\mathrm{N}=663)$.

\begin{tabular}{|c|c|c|c|c|c|c|c|}
\hline \multirow[t]{2}{*}{ Baseline variable } & \multicolumn{2}{|c|}{$\begin{array}{c}\text { Attendees } \\
\mathrm{N}=409\end{array}$} & \multicolumn{2}{|c|}{$\begin{array}{c}\text { Non-Attendees } \\
\mathrm{N}=140\end{array}$} & \multicolumn{2}{|c|}{$\begin{array}{c}\text { Deceased } \\
\mathrm{N}=114\end{array}$} & \multirow[b]{2}{*}{$\mathrm{p}$} \\
\hline & $\mathrm{n}$ & $(\%)$ & $\mathrm{n}$ & $(\%)$ & $\mathrm{n}$ & $(\%)$ & \\
\hline Age & & & & & & & $<0.001$ \\
\hline $65-79$ & 112 & $(27)$ & 29 & $(21)$ & 13 & $(11)$ & \\
\hline $80-89$ & 233 & $(57)$ & 71 & $(51)$ & 55 & $(48)$ & \\
\hline$\geq 90$ & 64 & (16) & 40 & (29) & 46 & $(40)$ & \\
\hline $\mathrm{ASA}$ & & & & & & & $<0.001$ \\
\hline $1-3$ & 337 & $(82)$ & 105 & $(75)$ & 61 & $(54)$ & \\
\hline $4-5$ & 69 & (17) & 34 & (24) & 49 & (43) & \\
\hline Not known & 3 & (1) & 1 & (1) & 4 & (4) & \\
\hline Number of regularly taken medications & & & & & & & $<0.001$ \\
\hline$<4$ & 87 & $(21)$ & 25 & $(18)$ & 4 & (3) & \\
\hline $4-10$ & 254 & $(62)$ & 84 & (60) & 72 & (64) & \\
\hline$>10$ & 68 & (17) & 31 & (22) & 37 & (33) & \\
\hline Not known & 0 & (0) & 0 & (0) & 1 & $(<1)$ & \\
\hline Diagnosis of memory disorder & & & & & & & 0.097 \\
\hline No & 297 & $(73)$ & 97 & (69) & 77 & $(68)$ & \\
\hline Yes & 111 & (27) & 43 & (31) & 34 & (30) & \\
\hline Not known & 1 & $(<1)$ & 0 & (0) & 3 & (3) & \\
\hline Mobility before fracture & & & & & & & $<0.001$ \\
\hline Outdoors unassisted & 246 & $(60)$ & 51 & $(36)$ & 25 & $(22)$ & \\
\hline Outdoors assisted & 148 & (36) & 65 & (46) & 72 & (63) & \\
\hline Indoors assisted & 9 & (2) & 20 & (14) & 10 & (9) & \\
\hline Unable to walk & 5 & (1) & 3 & (2) & 2 & (2) & \\
\hline Not known & 1 & $(<1)$ & 1 & (1) & 5 & (4) & \\
\hline Living before fracture & & & & & & & $<0.001$ \\
\hline Home without organized home care & 190 & $(47)$ & 44 & $(31)$ & 24 & $(21)$ & \\
\hline Home with organized home care & 131 & (32) & 39 & (28) & 24 & (21) & \\
\hline Assisted living accomodation & 33 & (8) & 22 & (16) & 24 & (21) & \\
\hline Institutionalized & 55 & (13) & 35 & $(25)$ & 39 & (34) & \\
\hline Not known & 0 & $(0)$ & 0 & (0) & 3 & (3) & \\
\hline eGFR & & & & & & & $<0.001$ \\
\hline Mild dysfunction, $(\geq 60)$ & 136 & (33) & 31 & $(22)$ & 16 & (14) & \\
\hline Moderate dysfunction (30-59) & 185 & (45) & 65 & $(46)$ & 54 & $(47)$ & \\
\hline Severe dysfunction $(<30)$ & 32 & $(8)$ & 13 & (9) & 28 & (25) & \\
\hline Not known & 56 & (14) & 31 & (22) & 16 & (14) & \\
\hline MNA-SF & & & & & & & $<0.001$ \\
\hline Normal & 240 & (59) & 54 & (39) & 22 & (19) & \\
\hline At risk of malnutrition & 147 & (36) & 73 & $(52)$ & 71 & $(62)$ & \\
\hline Malnourished & 20 & $(5)$ & 12 & (9) & 14 & (12) & \\
\hline Not known & 2 & (1) & 1 & (1) & 7 & $(6)$ & \\
\hline MNA-LF & & & & & & & $<0.001$ \\
\hline Normal & 150 & (37) & 27 & (19) & 9 & (8) & \\
\hline At risk of malnutrition & 165 & (40) & 67 & (48) & 65 & $(57)$ & \\
\hline Malnourished & 11 & (3) & 10 & (7) & 13 & (11) & \\
\hline Not known & 83 & (20) & 36 & (26) & 27 & (24) & \\
\hline
\end{tabular}

Differences between groups were tested by Pearson chi-square test or Fisher's exact test. 
Table 2. Post-void residual volume $\geq 160 \mathrm{ml}$ at outpatient assessment among women $(\mathrm{N}=409)$.

\begin{tabular}{|c|c|c|c|c|c|c|}
\hline & \multicolumn{6}{|c|}{ Women $(\mathrm{N}=409)$} \\
\hline & \multicolumn{3}{|c|}{$\begin{array}{c}\geq 160 \mathrm{ml} \\
(\mathrm{n}=64)\end{array}$} & \multicolumn{3}{|c|}{ Age-adjusted } \\
\hline & $\mathrm{N}$ & $\mathrm{n}$ & $(\%)$ & $\mathrm{p}$ & OR & $(95 \% \mathrm{CI})$ \\
\hline \multicolumn{7}{|l|}{ Baseline } \\
\hline Age & 409 & 64 & (16) & & 1.03 & $(0.98-1.07)$ \\
\hline Age & & & & 0.650 & & \\
\hline $65-79$ & 112 & 15 & (13) & & 1.00 & \\
\hline $80-89$ & 233 & 40 & (17) & & 1.34 & $(0.71-2.55)$ \\
\hline$\geq 90$ & 64 & 9 & (14) & & 1.06 & $(0.43-2.58)$ \\
\hline Number of regularly taken medications & & & & 0.265 & & \\
\hline$<4$ & 87 & 9 & (10) & & 1.00 & \\
\hline $4-10$ & 254 & 42 & (17) & & 1.67 & $(0.78-3.60)$ \\
\hline$>10$ & 68 & 13 & (19) & & 2.02 & $(0.81-5.07)$ \\
\hline eGFR & & & & 0.546 & & \\
\hline Mild dysfunction, $(\geq 60)$ & 103 & 16 & (16) & & 1.00 & \\
\hline Moderate dysfunction (30-59) & 264 & 44 & (17) & & 0.85 & $(0.43-1.69)$ \\
\hline Severe dysfunction $(<30)$ & 37 & 3 & (8) & & 0.31 & $(0.08-1.26)$ \\
\hline Not known & 5 & 1 & (20) & & 1.07 & $(0.11-10.6)$ \\
\hline Urinary incontinence & & & & 0.028 & & \\
\hline No & 167 & 17 & (10) & & 1.00 & \\
\hline Yes & 233 & 46 & (20) & & 2.09 & $(1.14-3.82)$ \\
\hline Not known & 9 & 1 & (11) & & 1.08 & $(0.13-9.21)$ \\
\hline Type of urinary incontinence & & & & $\mathbf{0 . 0 3 0}$ & & \\
\hline None & 216 & 25 & (12) & & 1.00 & \\
\hline Stress & 42 & 5 & (12) & & 1.02 & $(0.37-2.84)$ \\
\hline Urgency & 82 & 20 & (24) & & 2.43 & $(1.26-4.69)$ \\
\hline Mixed & 69 & 14 & $(20)$ & & 1.93 & $(0.94-3.97)$ \\
\hline Nocturia & & & & 0.303 & & \\
\hline No (0-1 times per night) & 49 & 4 & (8) & & 1.00 & \\
\hline Yes (at least 2 times per night) & 307 & 52 & (17) & & 2.20 & $(0.75-6.40)$ \\
\hline Not known & 53 & 8 & (15) & & 1.83 & $(0.51-6.58)$ \\
\hline Fecal incontinence & & & & 0.003 & & \\
\hline No & 348 & 47 & (14) & & 1.00 & \\
\hline Yes & 53 & 17 & $(32)$ & & 3.01 & $(1.56-5.80)$ \\
\hline Not known & 8 & 0 & $(0)$ & & - & \\
\hline Constipation & & & & 0.210 & & \\
\hline No & 188 & 24 & (13) & & 1.00 & \\
\hline Yes & 216 & 40 & (19) & & 1.47 & $(0.84-2.57)$ \\
\hline Not known & 5 & 0 & $(0)$ & & - & \\
\hline MMSE & & & & 0.025 & & \\
\hline $24-30$ & 145 & 16 & (11) & & 1.00 & \\
\hline$<24$ & 247 & 42 & (17) & & 1.55 & $(0.81-2.95)$ \\
\hline Not known & 17 & 6 & (35) & & 4.12 & $(1.32-12.9)$ \\
\hline GDS-15 & & & & 0.141 & & \\
\hline $0-6$ & 317 & 51 & (16) & & 1.00 & \\
\hline $6-15$ & 70 & 7 & (10) & & 0.55 & $(0.23-1.26)$ \\
\hline Not known & 22 & 6 & (27) & & 1.82 & $(0.67-4.91)$ \\
\hline
\end{tabular}


PADL

No difficulties (6)

Difficulties (0-5)

Not known

IADL

No difficulties (8)

Difficulties (0-7)

Not known

TUG time

TUG

Normal (1-2)

Moderately abnormal (3-4)

Markedly abnormal (5)

Not known

Grip strength in stronger hand

Normal

$<16 \mathrm{~kg}$

Not known

EMS

14-20

6-13

$0-5$

Not known

MNA-SF

Normal

At risk of malnutrition

Malnourished

Not known

MNA-LF

Normal

At risk of malnutrition

Malnourished

Not known $\begin{array}{lll}130 & 10 & (8)\end{array}$

$273 \quad 53 \quad(19)$

$\begin{array}{lll}6 & 1 & (17)\end{array}$

$\begin{array}{lll}63 & 6 & (10)\end{array}$

$340 \quad 57 \quad(17)$

$\begin{array}{lll}6 & 1 & (17)\end{array}$

$345 \quad 44 \quad(13)$

$138 \quad 12 \quad$ (9)

$171 \quad 23 \quad(14)$

$\begin{array}{lll}26 & 7 & (27)\end{array}$

$\begin{array}{lll}74 & 22 & (30)\end{array}$

$89 \quad 17 \quad(19)$

$248 \quad 32 \quad(13)$

$72 \quad 15 \quad(21)$

$256 \quad 28 \quad(11)$

$87 \quad 16 \quad(18)$

$\begin{array}{lll}34 & 13 & (38)\end{array}$

$\begin{array}{lll}22 & 7 & \text { (32) }\end{array}$

$159 \quad 18 \quad(11)$

$192 \quad 31 \quad(16)$

$\begin{array}{lll}53 \quad 13 & (25)\end{array}$

$5 \quad 2 \quad(40)$

$128 \quad 18 \quad(14)$

$184 \quad 23 \quad(13)$

$\begin{array}{lll}34 & 11 & (32)\end{array}$

$\begin{array}{lll}63 & 12 & (19)\end{array}$
0.005

1.00

2.81 (1.34-5.87)

$2.36 \quad(0.25-22.3)$

0.277

1.00

$1.72 \quad(0.68-4.34)$

$1.75 \quad(0.17-17.7)$

1.02 (1.004-1.03)

$<0.001$

1.00

$1.58 \quad(0.75-3.35)$

$3.76 \quad(1.30-10.8)$

$4.27 \quad(1.93-9.44)$

0.151

1.00

$0.54 \quad(0.28-1.06)$

$0.97 \quad(0.44-2.15)$

$<0.001$

1.00

$1.86 \quad(0.94-3.67)$

$5.12 \quad(2.29-11.4)$

$3.86 \quad(1.44-10.4)$

0.041

1.00

$1.43 \quad(0.76-2.70)$

2.44 (1.09-5.44)

$4.76 \quad(0.74-30.8)$

0.034

1.00

$0.83 \quad(0.42-1.62)$

$2.71 \quad$ (1.12-6.59)

$1.39 \quad(0.62-3.12)$

Differences between groups (p) were analyzed by Fisher's exact test. In logistic regression models variables were entered simultaneously into the model. Results were shown by odds ratios (OR) with $95 \%$ confidence intervals (CI). 


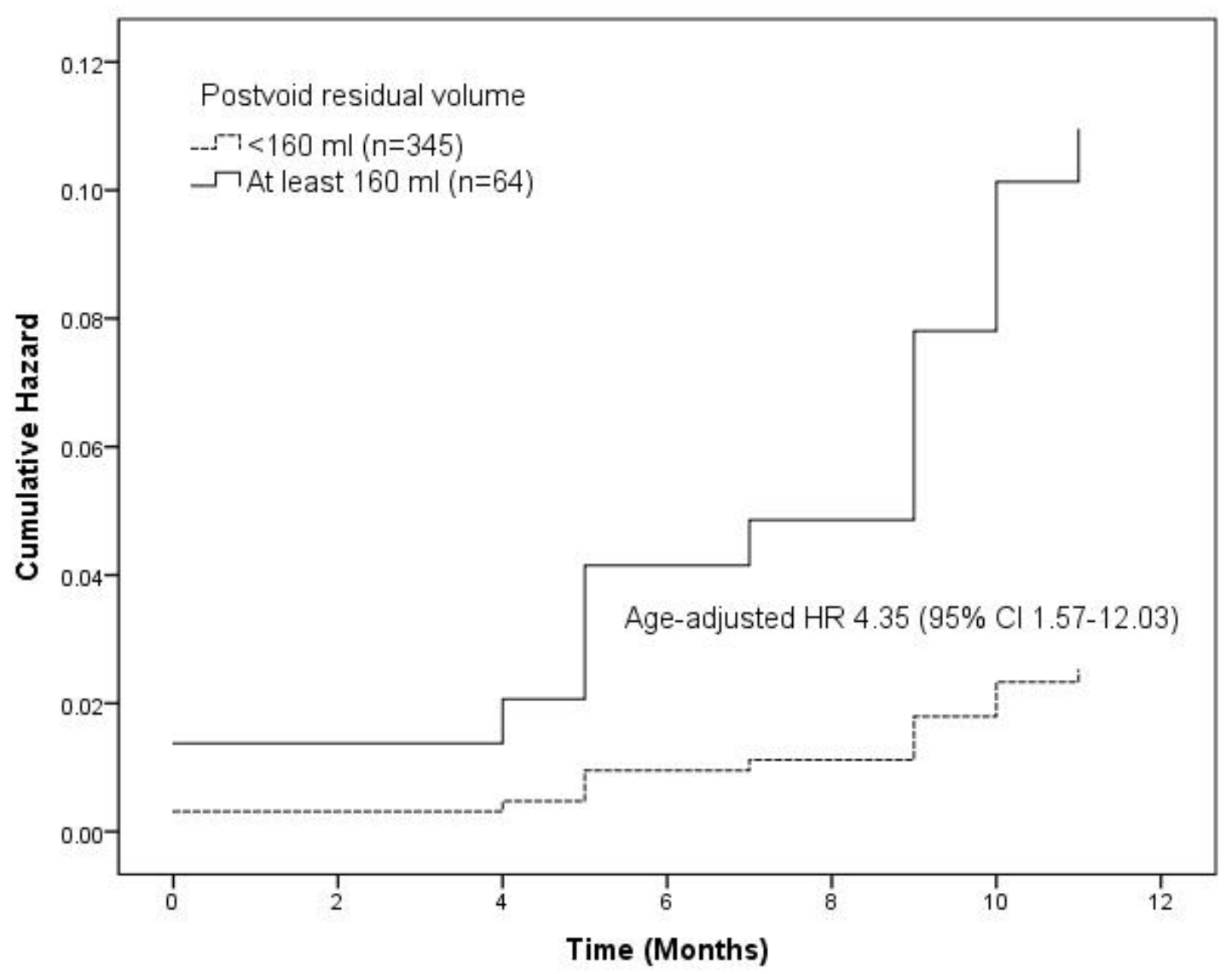

One year follow-up time from hip fracture to death or to the end of follow up 31 st Aug 2015 